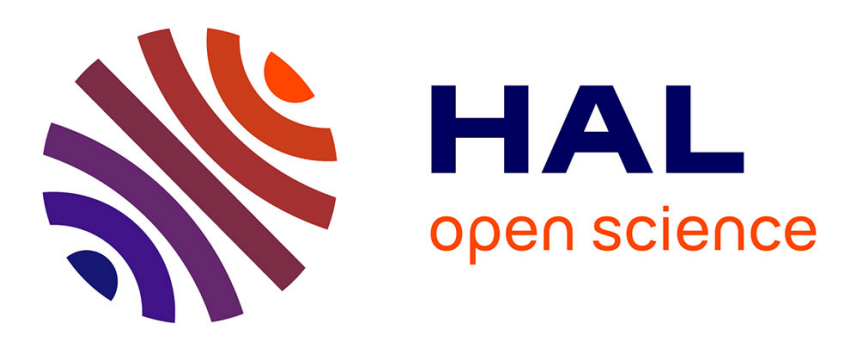

\title{
Measurements of high strain rate properties of polymers using an expanding ring method
}

\author{
N. Al-Maliky, D. Parry
}

\section{To cite this version:}

N. Al-Maliky, D. Parry. Measurements of high strain rate properties of polymers using an expanding ring method. Journal de Physique IV Proceedings, 1994, 04 (C8), pp.C8-71-C8-76. 10.1051/jp4:1994810 . jpa-00253340

\section{HAL Id: jpa-00253340 https://hal.science/jpa-00253340}

Submitted on 1 Jan 1994

HAL is a multi-disciplinary open access archive for the deposit and dissemination of scientific research documents, whether they are published or not. The documents may come from teaching and research institutions in France or abroad, or from public or private research centers.
L'archive ouverte pluridisciplinaire HAL, est destinée au dépôt et à la diffusion de documents scientifiques de niveau recherche, publiés ou non, émanant des établissements d'enseignement et de recherche français ou étrangers, des laboratoires publics ou privés. 


\title{
Measurements of high strain rate properties of polymers using an expanding ring method
}

\author{
N. Al-Maliky and D.J. Parry
}

Department of Physics, Loughborough University of Technology, Loughborough, Leics LEII 3TU, U.K.

\begin{abstract}
Résumé Trois polymères d'application ingénieure (HDPE, UHMWPE, et Nylatron GS) ont été étudiés à très grande vitesse de déformation (excédant $104 / \mathrm{s}$ ). On utilisait une technique d'anneau dilaté, qui nécessite le placement d'un fin anneau de polymère, comme bague glissante autour d'un cylindre/creux ayant les murs épais. Un chargement par onde engendré par un fil explosif, abouti au pulse de pression qui s'exerce sur le mur interne du cylindre. Ce pulse se propage à travers le mur du cylindre et est transferé partielement dans l'anneau. L'anneau se déplace á une grande vitesse du cylindre presque instantanément et en conséquence décélère sous une tension quasiment uniaxiale dû à la contrainte circonférentielle. L'anneau a été photographé avec un appareil de grande vitesse (des cadres de $10^{5}$ à $10^{6} / \mathrm{s}$ ) et on a pris des mesures duquels les vrais propriétés de déformation et de contrainte étaient déterminés. On a comparé les résultats obtenus du barre d'Hopkinson, en conditions quasistatiques avec les experiénces de l'anneau dilaté.
\end{abstract}

Abstract Three engineering polymers (HDPE, UHMWPE, and Nylatron GS) have been studied at very high tensile strain rates (above $10^{4} / \mathrm{s}$ ) using an expanding ring technique, which involves placing a thin ring of polymer as a sliding fit around a hollow thick-walled cylinder. A blast wave generated by an exploding wire results in a pressure pulse acting on the internal wall of the cylinder. This pulse propagates through the cylinder wall and is partially transferred into the ring. The ring moves virtually instantaneously at a high velocity away from the cylinder and then decelerates under almost uniaxial tension as a result of the hoop stress. Measurements were made by photographing the ring using a high speed camera at $10^{5}$ to $10^{6}$ frames/s, from which the true stress-strain properties were determined. Comparisons have been made between results obtained from quasi static, split Hopkinson pressure bar, and expanding ring experiments.

\section{INTRODUCTION}

The mechanical behaviour of most materials is strongly dependent on strain rate [1]. For polymers, not only does the flow stress at a given strain increase with increasing strain rate, but also the Young's modulus under quasi-static conditions is appreciably lower than at high strain rate [2].

Commercial equipment is available for obtaining rates of strain up to a few hundred per second, eg drop weight and pendulum apparatus (Charpy and Izod). To achieve higher strain rates research laboratory designed equipment is used, the principal type being the split-Hopkinson pressure bar (SHPB) system $[3,4]$. The SHPB method is capable of achieving very high compressive strain rates, typically in the range 
$10^{2} / \mathrm{s}$ to $10^{4} / \mathrm{s}$, using small disc-shaped specimens. However, much care must be taken in the selection of the specimen's dimensions and the specimen/pressure bar lubricant in order to minimise the inertial and frictional effects which can cause inaccurate flow-stress measurements $[5,6]$. The SHPB method can also be used to measure high strain-rate tensile properties, but inertial effects tend to limit the strain rate to about $10^{3 / \mathrm{s}}$ for the dogbone-shaped specimens [7]. In an attempt to study the tensile behaviour of polymers at strain rates greater than those possible in the SHPB method, the authors have used a method of impact loading called the exploding wire technique $[8,9]$.

\section{EXPERIMENTAL}

\subsection{The Exploding Wire Technique (EWT)}

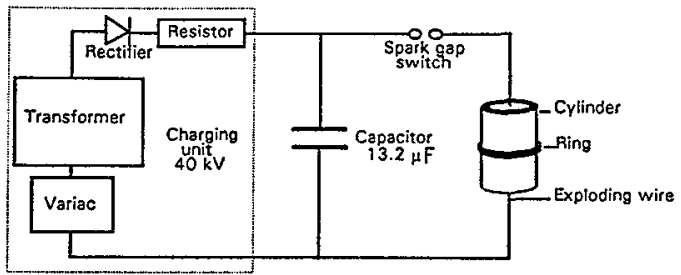

Figure 1 The basic exploding wire system

As used by the present authors, the EWT involves the production of a cylindrical blast wave of low risetime $(<1 \mu \mathrm{s})$, short duration $(\sim 5 \mu \mathrm{s})$, and high reflection pressure $(>1 \mathrm{kbar})$, which loads the inside surface of a hollow cylinder, typically 70 to $130 \mathrm{~mm}$ in length. The blast wave is generated in atmospheric-pressure air by exploding a copper wire placed along the axis of the cylinder. The wire is almost instantaneously vaporised (in $\sim 1 \mu \mathrm{s}$ ) by the rapid discharge of up to $10 \mathrm{~kJ}$ of stored energy from a low-inductance $13.2 \mu \mathrm{F}$ capacitor charged at up to $40 \mathrm{kV}$. The general arrangement is shown in Figure 1. The switch is a pressurised dry-nitrogen filled spark gap which can be triggered by an external pulse so as to discharge the capacitor through the wire. The material being studied is in the form of a thin ring which is a sliding fit around the cylinder. A full description of how the ring expands during an experiment, and how this expansion is used to determine the stress/strain properties of the ring is given later.

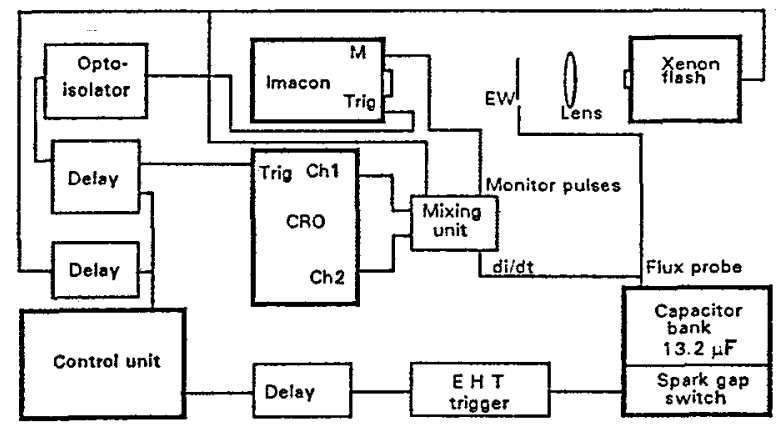

Figure 2 The high-speed photography and synchronisation system

It is essential that the blast wave produced by the exploding wire is cylindrically symmetric so that the inner surface of the cylinder is loaded uniformly and simultaneously. High-speed photography has been used to study the radial expansion of the blast wave without any cylinder being present, as well as for subsequent observations of the movement of the cylinder and ring. 
Figure 2 shows a schematic diagram of the exploding wire operating system set up for high-speed photography based on a single-lens schlieren arrangement. The camera is a Hadland. Imacon image converter camera operating at framing rates between $10^{5}$ and $10^{6}$ frames $/ \mathrm{s}$, and the light source is either a Hadland $50 \mu$ s duration xenon flash unit or a simple electronic flash gun giving a $200 \mu$ s flash output. The control unit sets the voltage on the capacitor bank and also provides pulses to enable the spark gap to initiate the discharge of the capacitor through the exploding wire (EW). Several delay units and an opto-isolator are incorporated to ensure correct synchronisation of the wire explosion with the flash, the camera, and the oscilloscope. The flash has to be fired before the explosion to enable the light output to reach a sufficient level for photography. By recording the camera monitor pulses on the oscilloscope for each shot, very accurate measurements of the framing rate were possible. Additionally, precise association of the individual camera frames with each stage of the explosion process was achieved by recording $\mathrm{di} / \mathrm{dt}$, the rate of change of the discharge current. Numerous experiments have previously been carried out [10], without a cylinder, which established that cylindrically symmetric blast waves are produced by the system. The experiments also showed that wires of diameter $22 \mathrm{swg}(0.71 \mathrm{~mm})$ or 24 swg $(0.56 \mathrm{~mm})$, with lengths of 50 to $130 \mathrm{~mm}$, were the most efficient for producing high velocity/high pressure blast waves.

\subsection{The Freely-Expanding Ring Tests}

The stress/strain properties of several polymers at high tensile strain rates have been determined using the freely-expanding thin ring technique. As shown in Figure 1, a thin polymer ring is placed as a sliding fit around a thick-walled polymer cylinder. The inner wall of the cylinder is then subjected to a blast wave generated by the exploding wire, resulting in a stress pulse which propagates through the cylinder wall. This stress pulse is partially transferred into the ring which subsequently moves almost instantaneously at a high velocity away from the cylinder and then decelerates as a result of the hoop stress. The stress state in the ring closely approximates to uniaxial tension.

For an expanding thin ring it can be shown that $[11,12]$ the true stress $\sigma$, true strain $\varepsilon$, and true strain rate $\partial \varepsilon / \partial t$, are given by

$$
\sigma=-\rho \mathrm{R} \partial^{2} \mathrm{R} / \partial \mathrm{t}^{2}, \varepsilon=\ln \left(\mathrm{R} / \mathrm{R}_{\mathrm{o}}\right), \partial \varepsilon / \partial \mathrm{t}=(\partial \mathrm{R} / \partial \mathrm{t}) / \mathrm{R}
$$

where $\rho$ is the material density, $R_{0}$ is the initial outer radius of the ring, and $R$ is the outer radius of the ring at time $t$. By recording the expansion of the ring using high-speed photography, the present authors have determined the stress/strain/strain rate tensile properties of the ring.

The polymer rings studied so far have been made from three types of engineering polymer: high density polyethylene (HDPE), ultra-high molecular weight polyethylene (UHMWPE) and Nylatron GS (a modified nylon 66). The rings had an external diameter of approximately $25 \mathrm{~mm}$, a breadth of $5 \mathrm{~mm}$, and a thickness 0.4 to $0.7 \mathrm{~mm}$. The cylinders on which the rings were placed were generally of length 70 to $100 \mathrm{~mm}$ and wall thickness of about $9 \mathrm{~mm}$. The choice of material for the cylinder is important so that sufficient momentum is transferred into the ring. A polymer cylinder of the same material as the ring provides the best impedance match, but numerous experiments have shown us that this is not the most important criterion at the cylinder strain rates of about $10^{3} / \mathrm{s}$ produced by the blast wave impact. What is essential is that the cylinders do not fracture during the time of observation of the ring deformation (about $100 \mu \mathrm{s})$.

\section{RESULTS AND DISCUSSION}

Figure 3 shows high speed photographs taken at framing rates of $10^{5} / \mathrm{s}$ for rings of UHMWPE and Nylatron, the rings being placed on cylinders of UHMPE. Each loading was produced by a $25 \mathrm{kV}$ capacitor discharge through an $80 \mathrm{~mm}$ long copper wire of diameter $22 \mathrm{swg}$. The UHMWPE ring can be seen to expand smoothly before starting to contract after about $80 \mu \mathrm{s}$. However, the nylatron ring has clearly fractured after about $40 \mu \mathrm{s}$. The UHMPE cylinders expanded much more slowly than the rings 

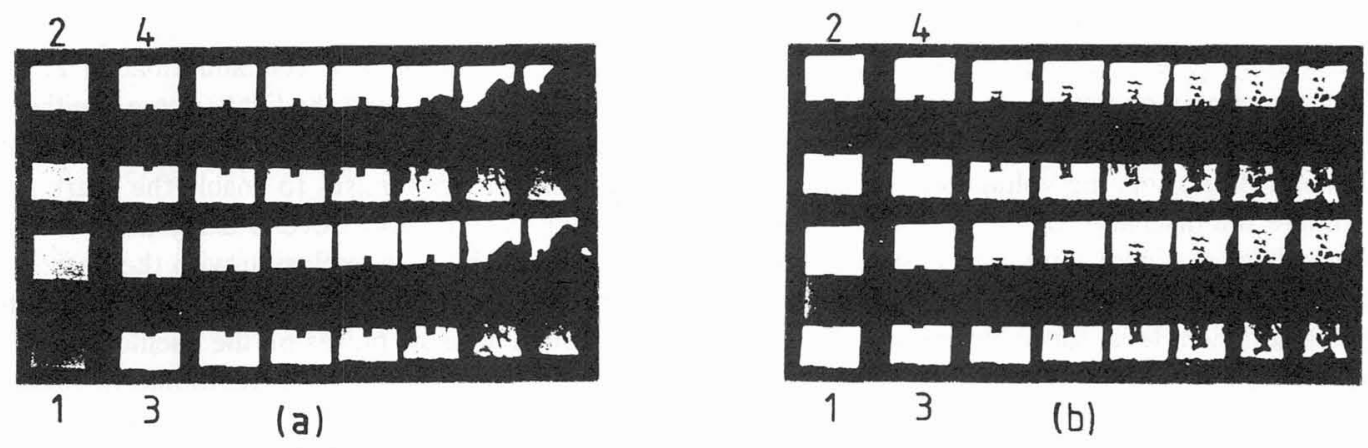

Figure 3 Imacon photographs at $10 \mu$ s framing intervals of expanding rings on UHMWPE cylinders: (a) UHMWPE, (b) Nylatron.

and did not fracture for at least $110 \mu$ s (at a hoop strain of about $26 \%$ ), so they did not interfere with the motion of the rings or the clarity of observation. In contrast, Nylatron cylinders fractured after about $30 \mu \mathrm{s}$ at a hoop strain of about $12 \%$ while for HDPE the corresponding values were $70 \mu \mathrm{s}$ and $20 \%$ strain. These strains are much lower than measured quasistatic tensile values. Pieces from fractured Nylatron or HDPE cylinders overtook the expanding ring obliterating the field of view and also caused unwanted secondary impacts.

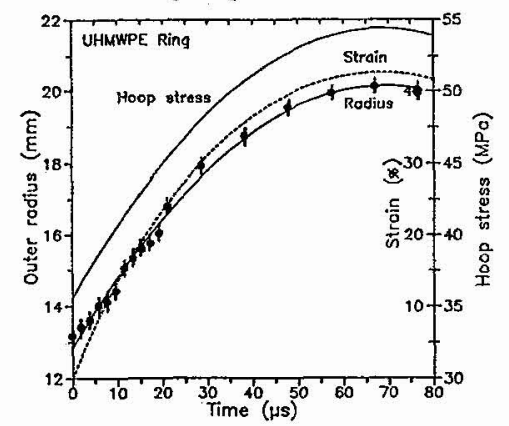

(a)

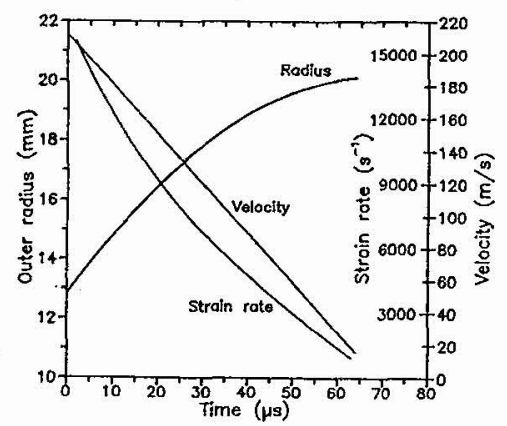

Figure 4 Analysis of an expanding UHMWPE ring. (a) Measured radius values against time together with derived velocity and strain rate. (b) Radius, strain and stress against time.

Figure 4 shows an analysis for an experiment with an UHMWPE ring. The external radius of the ring was measured as a function of time for separate experiments using $10^{5} \mathrm{frames} / \mathrm{s}$ and $5 \times 10^{5} \mathrm{frames} / \mathrm{s}$ (for greater resolution) and the results combined. The best fit to the radius/time data was found to be a second order polynomial. This was then used to determine the velocity and acceleration of the ring. As can be seen in Figure 4, the ring velocity decreased linearly with time from a maximum of $200 \mathrm{~m} / \mathrm{s}$ to $20 \mathrm{~m} / \mathrm{s}$ after about $60 \mu \mathrm{s}$, just before the ring reached its maximum radius. An initial strain rate of $15,000 / \mathrm{s}$ was achieved, which decreased to about $1500 / \mathrm{s}$ after $60 \mu \mathrm{s}$, when the strain was nearly at its maximum value of about $43 \%$, and the hoop stress was $54 \mathrm{MPa}$.

Representative true stress/strain curves under compressive quasistatic, compressive SHPB, and tensile expanding ring conditions are given in Figure 5, for strains up to a maximum of $30 \%$. The true strain rate in any particular SHPB experiment is reasonably constant for the polymer specimens (of diameter $6 \mathrm{~mm}$ and thickness $3 \mathrm{~mm}$ ), except when the strain exceeds about $30 \%$, after which the strain rate can increase appreciably. For example, the actual strain rate achieved for Nylatron was about $20,000 / \mathrm{s}$, when the true strain had reached about $90 \%$. The mean strain rate for that test was then about $11,500 / \mathrm{s}$. However, this gives a false impression of the mean strain rate up to $30 \%$ strain, which was just $8440 / \mathrm{s}$. For all SHPB tests where the final strain exceeded $30 \%$, the mean strain rate for the experiment was taken as that up to $30 \%$ strain; this can be regarded as giving a more realistic strain rate for making deductions regarding strain rate sensitivity in the low strain region. 

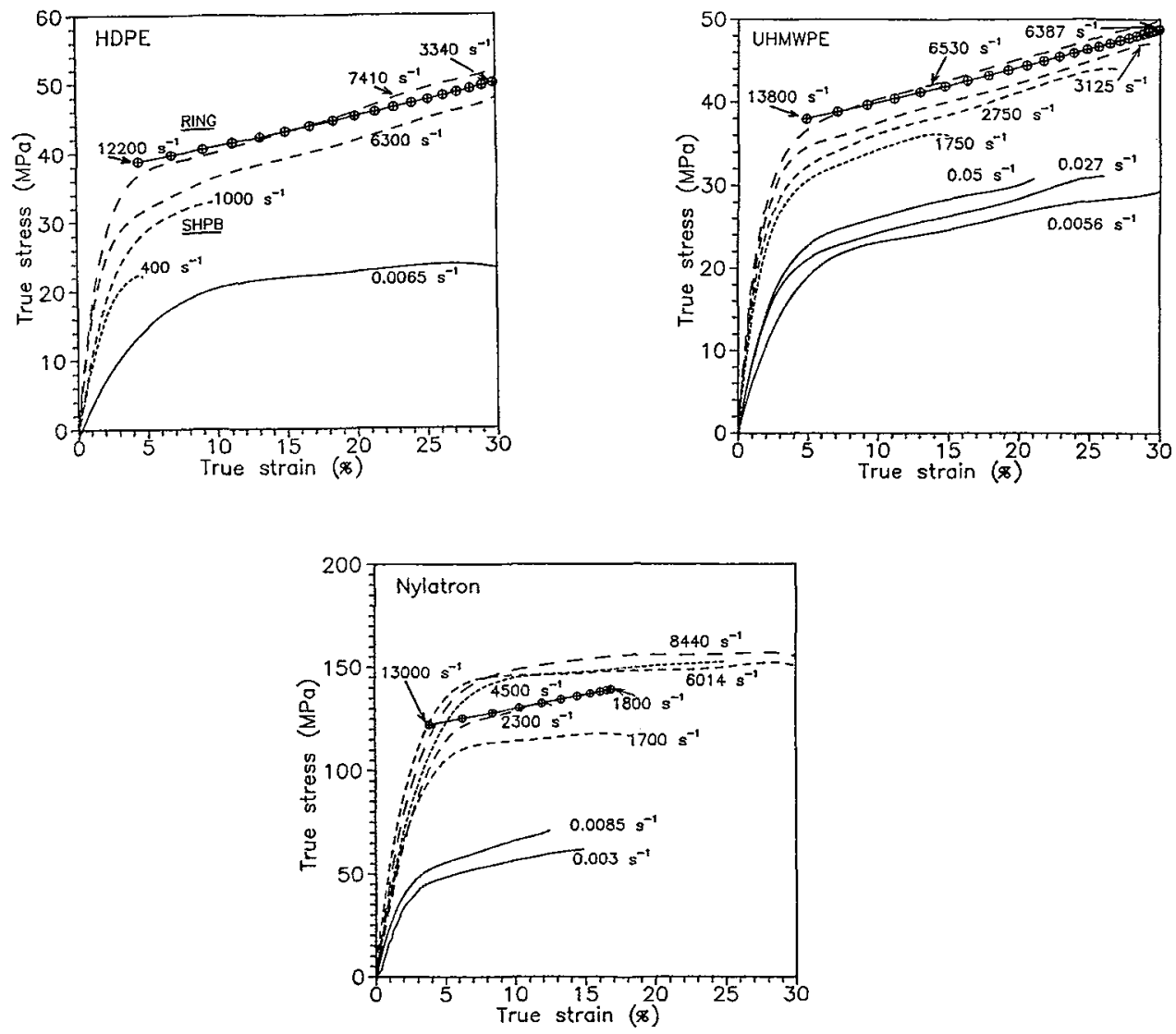

Figure 5 Stress/strain curves for quasi-static, SHPB and expanding ring experiments.

In the ring experiments, there is some uncertainty in the polynomial fit for the first few microseconds, so the results have been plotted only after about 3\% strain. The actual strain rates for the start and end values of the plots are also shown. The HDPE and UHMWPE rings did not fracture during the experiments, while Nylatron fractured after about $18 \%$ strain. It can be seen that for HDPE and UHMWPE the flow stress increases continuously with strain rate for the quasistatic and SHPB measurements, and that the ring results fit in well with this trend. However, for Nylatron, the ring results lie below those corresponding to the highest strain rate SHPB values.

The variation of flow stress with strain rate can be seen more clearly in Figure 6, where the flow stress at $5 \%$ strain is plotted as a function of log strain rate for all the experiments. For the ring values, the strain rates used are those corresponding to 5\% strain. HDPE and UHMWPE show a linear increase of flow stress from about $3 \times 10^{-3} / \mathrm{s}$ up until about $3 \times 10^{3} / \mathrm{s}$, above which the flow stress increases more rapidly with strain rate. These results are in reasonable agreement with other published worth for HDPE [13, 14, 15], and imply that a simple thermal activation model can be used to describe the behaviour up to $3 \times 10^{3} / \mathrm{s}$. The ring measurements extend the range and confirm the trend shown by the higher strain rate SHPB results. Nylatron shows a linear increase of flow stress with log strain rate from about $3 \times 10^{-3} / \mathrm{s}$ to about $5 \times 10^{3} / \mathrm{s}$. The flow stress then increases more rapidly up to about $7 \times 10^{3} / \mathrm{s}$, above which it decreases until at $10^{4 / \mathrm{s}}$ it has the value it had at about $4 \times 10^{3 / \mathrm{s}}$. The expanding ring results again confirm the trend shown by the SHPB data. Similar observations of a decrease in flow stress have been made previously for nylon 66 [14], where compressive strain rates in excess of $10^{4} / \mathrm{s}$ were achieved by 


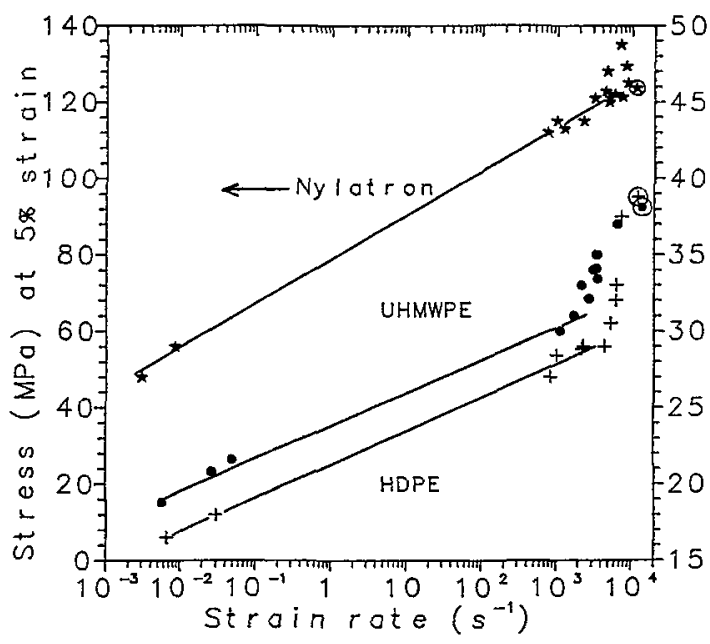

Figure 6 Stress at 5\% strain against log strain rate for HDPE, UHMWPE and Nylatron GS.

using a direct impact Hopkinson Bar system. No satisfactory explanation for this flow stress decrease has yet been put forward for the SHPB results; for the tensile ring tests, the stress reduction may be associated with a transition to more brittle behaviour with localised yielding or fracture causing weakening before catastrophic failure occurs after about $20 \%$.

\section{CONCLUSIONS}

The expanding ring method has proved to be very effective in producing high tensile rates of up to $1.4 \times 10^{4} / \mathrm{s}$ in several polymers. The results have been shown to be in good agreement with compressive SHPB measurements indicating similar tensile and compressive high strain rate behaviour. With greater energy put into the exploding wire it should be possible to achieve even higher tensile strain rates.

\section{REFERENCES}

[1] Blazynski T Z, Materials at High Strain Rates (Elsevier Applied Sciences, London, 1987).

[2] Parry D J, Stewardson H R and Ahmad S H, J de Physique C3, 49 (1988) 689-694.

[3] Zukas J S, Impact Dynamics (Wiley and Sons, New York, 1982).

[4] Parry D J and Walker A J, IOP Short Meetings Series No 16 (1988) 111-120.

[5] Bertholf L D and Karnes C H, J Mech Phys Solids 23 (1975) 1-19.

[6] Gorham D A, J de Physique IV, C3, 1 (1991) 411-418.

[7] Ellwood S, Griffiths L J and Parry D J, J Phys E: Sci Instrum 15 (1982) 1169-1172.

[8] Ensminger R R and Fyfe I M, J Mech Phys Solids 14 (1966) 231-238.

[9] Swift R P and Fyfe I M, J Appl Mech, 37 (1970) 1134-1140.

[10] Griffiths L J, Parry D J and Stewardson H R, Int Symp on Intense Dynamic Loading and its Effects, Beijing (Science Press, Beijing, 1986) 269-275.

[11] Hoggat C R and Recht R F, Exp Mech, 9 (1969) 441-448.

[12] Warnes R H, Karpp R R and Follansbee P S, J de Physique C5, 46 (1985) 583-590.

[13] Briscoe B J and Nosker R W, Wear 95 (1984) 241-262.

[14] Walley S M, Field J E, Pope P H and Safford N A, J de Physique III, 1 (1991) 1889-1925.

[15] Dioh N N, Leevers P S and Williams J G, Polymer $\underline{34}$ (1993) 4230-4234. 